\title{
Dynamic Voltage Restorer Based 5-Level Flying Capacitor Multilevel Converter For Power Quality Improvement
}

\author{
N. Damodaram ${ }^{1}$, K. Lokanadham ${ }^{2}$ \\ ${ }^{1}$ M.Tech (PE\&ED) Student, Dept. of EEE, SVCET, India \\ ${ }^{2}$ Associate Professor, Dept. of EEE, SVCET, India
}

\begin{abstract}
This paper presents the application of dynamic voltage restorers (DVR) on power distribution systems for mitigation of voltage sags, harmonics and imbalances at sensitive loads. The dynamic voltage restorer (DVR) has become popular as a cost effective solution for the protection of sensitive loads from voltage sags and swells. It would be advantageous that a DVR could also be used to compensate any steady state load voltage harmonics, since this would increase the Power Quality. The DVR, which is based on a five-level flying-capacitor voltage Source converter (VSC), has been proved suitable for the task of compensating voltage disturbances. The performance of the DVR depends on control technique involved. This paper presents the control system based on the so-called repetitive control. Unlike other control schemes with a comparable range of applicability, only one controller is needed to cancel out all three disturbances simultaneously, while exhibiting good dynamic performance. To evaluate the quality of the load voltage during the operation of DVR, Total Harmonic Distortion (THD) is calculated. MATLAB are used to carry out all modelling aspects of the repetitive controller and test system. Simulation results show that the control approach performs very effectively and yields excellent voltage regulation.
\end{abstract}

KEYWORDS: Dynamic voltage restorer (DVR), flying capacitor multilevel converter, power quality (PQ), repetitive control, voltage sags.

\section{INTRODUCTION}

Power quality (PQ) has become an important issue over the past two decades due to the relentless integration of sensitive loads in electrical power systems, the disturbances introduced by nonlinear loads, and the rapid growth of renewable energy sources. Arguably, the most common PQ disturbance in a power system is voltage sags [1], but other disturbances, such as harmonic voltages and voltage imbalances, may also affect end user and utility equipment leading to production downtime and, in some cases, equipment terminal damage. The dynamic voltage restorer (DVR) is one of the most efficient and economic devices to compensate voltage sags [2]. The DVR is basically a voltage-source converter in series with the ac grid via an interfacing transformer, conceived to mitigate voltage sags and swells [3]. For low-voltage applications, DVRs based on two-level converters are normally used [4] and, therefore, much of the published literature on DVRs deals with this kind of converter. Nevertheless, for higher power applications, powerelectronic devices are usually connected to the Medium voltage (MV) grid and the use of two-level voltage converters becomes difficult to justify owing to the high voltages that the switches must block.

One solution is to use multilevel voltage-source converters which allow high power-handling capability with lower harmonic distortion and lower switching power losses than the two-level converter [5]. Among the different topologies of multilevel converters, the most popular are: neutral-point-clamped converters (NPC), flying-capacitor converters (FC), and H-bridge converters [6]. NPC converters require clamping diodes and are prone to voltage imbalances in their dc capacitors. The H-bridge converter limitations are the large number of individual inverters and the number of isolated dc voltage sources required. The main drawback of FC converters is that the number of capacitors increases with the number of levels in the output voltage.

In the past few years, research work has been reported on the use of FC-converter topology for flexible ac transmission system (FACTS) applications. In [5], a unified power-flow controller (UPFC) based on a five-level FC 


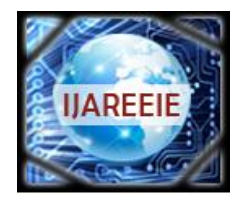

ISSN (Print) : $2320-3765$

ISSN (Online): 2278 - 8875

\title{
International Journal of Advanced Research in Electrical, Electronics and Instrumentation Engineering
}

\author{
(An ISO 3297: 2007 Certified Organization)
}

\section{Vol. 3, Issue 8, August 2014}

multilevel converter is proposed for power-flow control. The shunt and series converters are operated by phase-shifted sinusoidal pulse-width modulation [10] where the control system uses several proportional-integral (PI) controllers implemented in the $d-q$ synchronous reference frame. Since in FC converters a specific voltage level can be obtained by several switching combinations, the control of the voltage capacitors is achieved by carefully choosing such combinations for either charging or discharging the capacitors and, hence, to balance the voltage capacitors. The flying capacitor voltage balance is achieved by comparing the capacitor voltages with the reference values by means of hysteresis comparators. These comparators govern the charge/discharge actions of the flying capacitors as a function of the voltage error. This balancing technique provides good dynamic performance compared with other methods.

This paper is organized as follows. The model of a five-level flying-capacitor DVR is presented in Section II. The complete control-scheme structure is studied in Section III, including the three different control subsystems, namely, the filter output voltage controller, the repetitive control structure for the load voltage, and the flying-capacitor voltage regulator scheme, as well as the modulation method used to operate the multilevel converter. Simulation results obtained by implementing the control system and the five-level flying-capacitor DVR in MATLAB are presented in Section IV. Finally, the main conclusions are given in Section V.

\section{LITEARTURE SURVEY:}

Research work has been reported on several DVR multilevel topologies, but so far, no work seems to have been published on DVRs by using FC multilevel converters. This paper focuses on the design of a closed loop control system for a DVR by using a five-level flying-capacitor converter, based on the so-called repetitive control. Repetitive control was originally applied to eliminate speed fluctuations in electric motors, but it has also been successfully used in power electronics applications, such as power factor control in three phase rectifiers and active-filter control.

\section{CONFIGURATION OF THE DVR}

A. Five-Level FC:

Fig. 1 shows two different topologies of the flying capacitor multilevel converter.

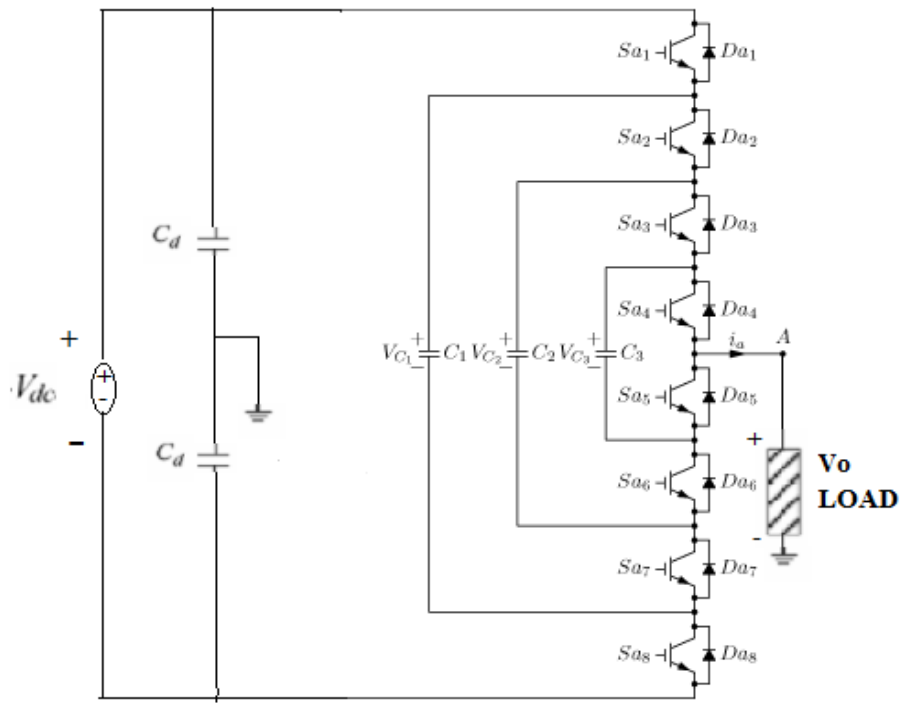

Fig.1: (a) Phase leg of flying-capacitor multilevel converter, (b) Switching tables.

\begin{tabular}{|c|c|c|c|c|}
\hline \multirow{2}{*}{$\mathrm{Vo}^{*}$} & \multicolumn{4}{|c|}{ Switching States } \\
\cline { 2 - 5 }$+\mathrm{S}_{\mathrm{a} 1}$ & $\mathrm{~S}_{\mathrm{a} 2}$ & $\mathrm{~S}_{\mathrm{a} 3}$ & $\mathrm{~S}_{\mathrm{a} 4}$ \\
\hline$+\mathrm{V}_{\mathrm{dc}} / 2$ & 1 & 1 & 1 & 1 \\
\hline \multirow{4}{*}{$+\mathrm{V}_{\mathrm{dc}} / 4$} & 1 & 1 & 1 & 0 \\
\cline { 2 - 5 } & 1 & 1 & 0 & 1 \\
\cline { 2 - 5 } & 1 & 0 & 1 & 1 \\
\cline { 2 - 5 } & 0 & 1 & 1 & 1 \\
\hline \multirow{5}{*}{0} & 1 & 1 & 0 & 0 \\
\cline { 2 - 5 } & 1 & 0 & 1 & 0 \\
\cline { 2 - 5 } & 0 & 1 & 1 & 0 \\
\cline { 2 - 5 } & 1 & 0 & 0 & 1 \\
\cline { 2 - 5 } & 0 & 1 & 0 & 1 \\
\cline { 2 - 5 } & 0 & 0 & 1 & 1 \\
\hline \multirow{5}{*}{$-\mathrm{V}_{\mathrm{dc}} / 4$} & 1 & 0 & 0 & 0 \\
\cline { 2 - 5 } & 0 & 1 & 0 & 0 \\
\cline { 2 - 5 } & 0 & 0 & 1 & 0 \\
\cline { 2 - 5 } & 0 & 0 & 0 & 1 \\
\hline$-\mathrm{V}_{\mathrm{dc}} / 2$ & 0 & 0 & 0 & 0 \\
\hline
\end{tabular}

The converter in Fig. 1(a) provides a three level output voltage and the flying capacitor $C_{1}$ is charged to $V_{\mathrm{dc}} / 2$, whereas Fig. 1(b) depicts a phase leg of a five-level flying-capacitor converter. One advantage of the flying capacitor multilevel converter topology is that the extension to converters with more than three levels is easier than in the neutral-point-clamped option. Reading the five level topology shown in Fig.1(b), the fling capacitor C1,C2,and C3 are charged to, $3 \mathrm{Vdc} / 4, \mathrm{Vdc} / 2$ and $\mathrm{Vdc} / 4$, respectively. Therefore, each switch must block only a voltage value equal to 

Electronics and Instrumentation Engineering

\author{
(An ISO 3297: 2007 Certified Organization)
}

\title{
Vol. 3, Issue 8, August 2014
}

$\mathrm{Vdc} / 4$, allowing the use of switches with lower-rated voltage compared with those in a conventional two-level converter. There are several switching combinations for the same given output voltage, which is known as switching redundancy [7]. These switching combinations result in different charging or discharging states of freedom for balancing the flying capacitor voltages. Comprehensive explanations of switching combinations and their results can be found in [7].

\section{B. DVR Connection System:}

The location of the DVR placed between the grid and the sensitive equipment is shown in Fig. 2. Different kinds of loads are assumed to be connected to the point of common coupling (PCC), such as linear loads (e.g., induction motors), nonlinear loads, and sensitive equipment. The DVR consists of a five-level flying-capacitor voltage-source converter and energy storage which provides the necessary voltage to the dc link. The series connection of the DVR is achieved by means of a coupling transformer. A passive $L C$ filter has been used to filter out the high harmonics generated by the PWM process.

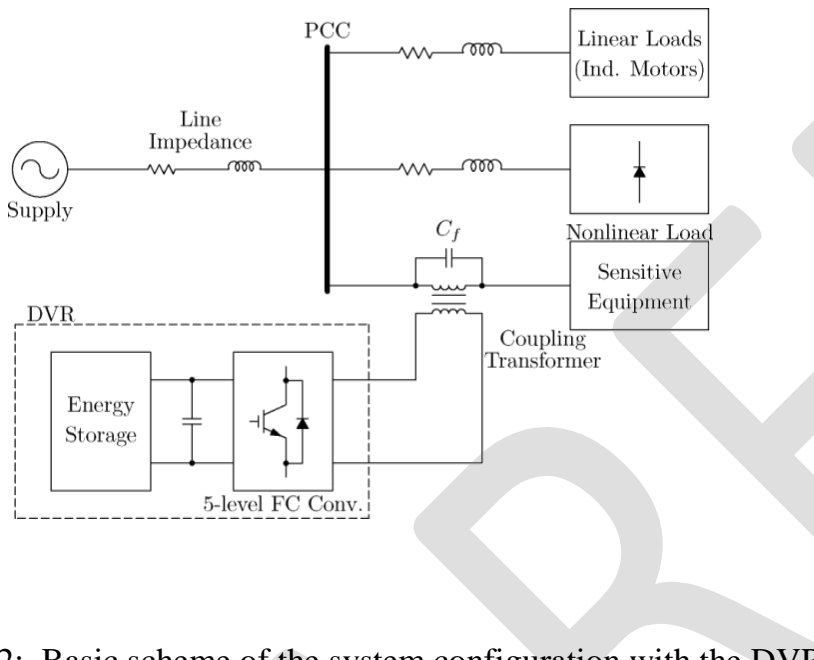

Fig.2: Basic scheme of the system configuration with the DVR

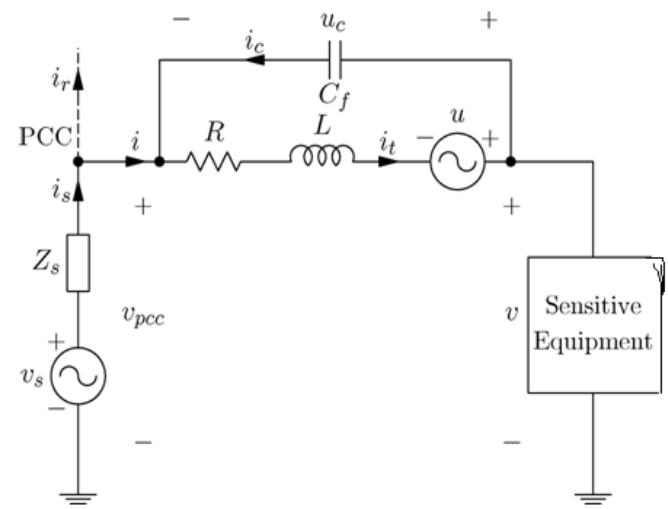

Fig. 3: Equivalent circuit for the DVRConnection system.

The equivalent circuit for the one-line system in Fig. 2 is depicted in Fig. 3, where $v_{s}$ is the supply voltage, $Z_{s}$ models the line impedance, $i_{s}$ is the current injected by the supply, which splits at the PCC into the current flowing through the sensitive equipment $i$ (this current is divided into the current through the coupling transformer $i t$ and the current through the filter capacitor $i_{c}$ ), and the current injected into the load $i_{r}$. The voltage $v_{\text {c c }}$ is the measured voltage at the PCC, $u$ stands for the DVR voltage which has been modeled as an ideal voltage source, the parameters $R$ and $L$ are the resistance and the leakage inductance, respectively, of the transformer whereas $C f$ is the capacitor used together with the coupling-transformer leakage inductance to filter out the high-frequency harmonics. Finally, $u c$ and $v$ are the voltages across the filter capacitor and the measured voltage across the sensitive equipment, respectively.

The equation of the sensitive-equipment voltage $v$ can be written as

$$
v(t)=v_{p c c}(t)+u_{c}(t)
$$

With the following state-variable model for the coupling transformer and the capacitor set:

$$
\frac{d\left[\begin{array}{l}
i_{t}(t) \\
u_{c(t)}
\end{array}\right]}{d x}=\left[\begin{array}{cc}
\frac{-R}{L} & \frac{-1}{L} \\
\frac{1}{C_{f}} & 0
\end{array}\right]\left[\begin{array}{l}
i_{t}(t) \\
u_{c}(t)
\end{array}\right]+\left[\begin{array}{cc}
\frac{1}{L} & 0 \\
0 & \frac{-1}{C_{f}}
\end{array}\right]\left[\begin{array}{l}
u(t) \\
i(t)
\end{array}\right]
$$




\title{
International Journal of Advanced Research in Electrical,
} Electronics and Instrumentation Engineering

\author{
(An ISO 3297: 2007 Certified Organization)
}

\section{Vol. 3, Issue 8, August 2014}

Where the state variables are $i_{t}(t)$ and $u_{c}(t)$, the control input is $u(t)$ and $i(t)$ is a disturbance input.

\section{CONTROL SYSTEM AND MODULATION STRATEGY}

\section{A. Control System for the Output Voltage of the LC Filter:}

System is a second-order filter with natural frequency $\omega_{n}=1 / \sqrt{ } L_{C} f$ and damping coefficient, $\xi=R / 2 . \sqrt{ } C f / L$. This filter exhibits a large resonance since the resistance $R$ usually has a very small value and, therefore, the damping coefficient is also very small. To overcome this problem, closed-loop control of the filter output voltage is required.

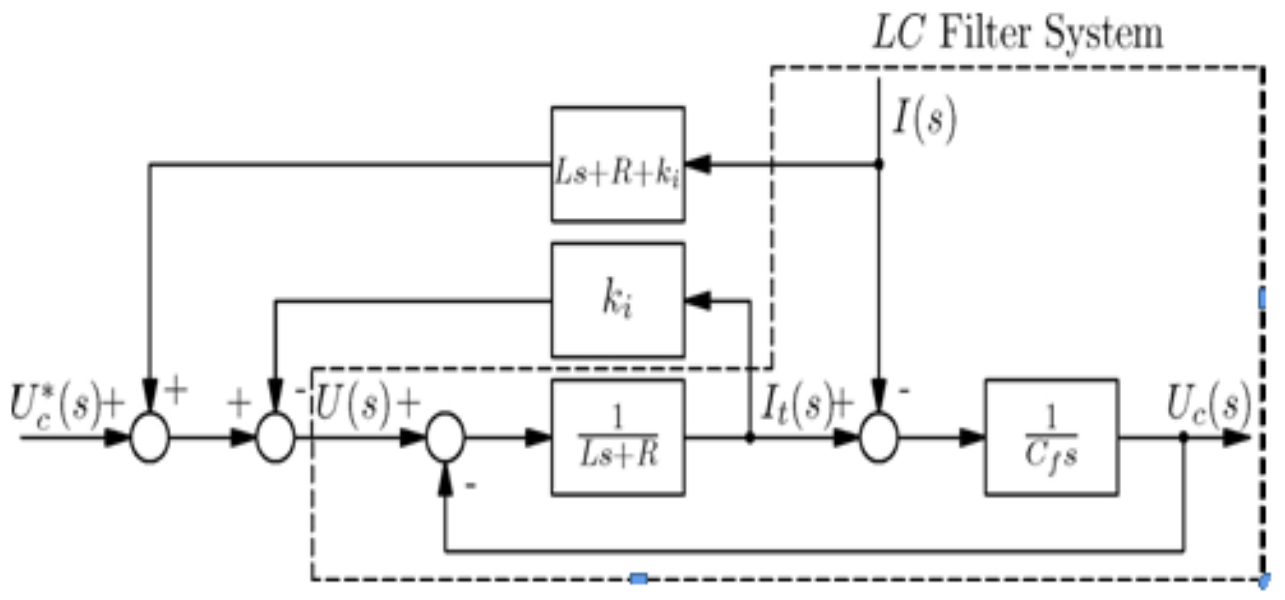

Fig. 4: Filter output voltage control scheme.

A proportional state-feedback controller plus a feed forward term are proposed for (2), with the following structure:

$$
u(t)=-\overbrace{\left[\begin{array}{ll}
k_{i} & k_{u}
\end{array}\right]}^{\mathbf{K}}\left[\begin{array}{c}
i_{t}(t) \\
u_{c}(t)
\end{array}\right]+u_{c}^{*}(t)+h(i(t))
$$

Where $\mathbf{K}$ is the feedback-gain matrix, $u_{*}(t)$ is the reference value, and the feed forward term $h(i(t))$ is a function of $i(t)$ which will be calculated to cancel out the effect of the disturbance $i(t)$ on the voltage $u_{c}(t)$.

In order to obtain the function $h(i(t))$, the Laplace transform is applied to (2) and (3), yielding

$$
U_{c}(s)=\frac{U_{c}^{*}(s)+H(s) I(s)-\left(L s+R+k_{i}\right) I(s)}{L C_{f} s^{2}+C_{f}\left(R+k_{i}\right) s+1}
$$

and $H(s)$ is chosen so that the term $I(s)$ has no effect in the capacitor voltage, which implies that $H(s)=L s+R+$ $k_{i}$ and $h(i(t))=L d i(t) / d t+\left(R+k_{i}\right) i(t)$.

\section{B. Phase-Shifted Pulse width Modulation:}

Several modulation methods have been used in multilevel converters according to the switching frequency [10]. In this paper, the well-known phase-shifted PWM method has been used since its implementation is simple and provides a certain degree of flying-capacitor voltage balance [7]. In a scheme with an $n$-level converter, $n_{-} 1$ triangular carriers with frequency $f_{c}$ have to be compared with a common sinusoidal modulating signal with frequency $f_{m}$. It is assumed that the carrier frequency is high enough to consider the modulating signal as a constant value in a period of the carrier. The switching instants are determined by the intersection between the modulating signal and the different carriers. A 

Electronics and Instrumentation Engineering

\author{
(An ISO 3297: 2007 Certified Organization)
}

\title{
Vol. 3, Issue 8, August 2014
}

shifting phase of $2 \pi /\left(n_{-} 1\right)$ is introduced in each carrier, which ensures an effective switching frequency of $\left(n \_1\right)$ $f_{c}$ and improves the total harmonic distortion of the output voltage, while the frequency modulation ratio yields $m f=($ $\left.n_{-1}\right) f_{c} / f_{m}$. For the three-phase case, three modulating signals with a shifting phase of 120 。 are used.

\section{Flying-Capacitor Voltage Control:}

In theory, the phase-shifted PWM method is able to balance the flying-capacitor voltages. Nevertheless, in practical implementations, there may be factors, such as asymmetrical conditions, different characteristic of power switches, etc, that produce voltage imbalances in the flying capacitors. For that reason, a control scheme, which guarantees the balance of the FC voltage, is required.

Voltage control is based on a closed-loop control scheme which corrects, for each switch, the modulating signal by adding a square-wave in order to increase or decrease the capacitor voltages.

\section{SIMULATION RESULTS}

The test system shown in Fig. 2 is used to carry out a comprehensive simulation scenario where the multilevel DVR and its control system show their worth

The following sequence of events is assumed to take place: 1) the nonlinear load is connected at time $t=0 \mathrm{~s}$ and the charging of the flying capacitors also starts at this point in time, a process that is fully completed at time $t=0.6 \mathrm{~s} ; 2$ ). At this point, the whole control system is activated and the DVR is connected to the grid together with the inductiveresistive load (sensitive load); 3) in the time period $0.7-1.1 \mathrm{~s}$, induction motor 1 is assumed to be connected with a constant rotor speed of 0.98 p.u.; 4) from $t=0.8 \mathrm{~s}$ to $t=1.1 \mathrm{~s}$, a two-phase-to-ground short-circuit fault is applied at the PCC via a 1.8- $\Omega$ resistor; 5) a second induction motor comes into operation right through the fault period, at $t=0.9$ $\mathrm{s}$ until the end of the simulation time; 6) the nonlinear load is disconnected at $t=1.3 \mathrm{~s}$ and, at this point in time, a second short-circuit fault applied at the PCC takes place; this time, there is a three-phase-to-ground fault, with a duration of $20 \mathrm{~ms}$. The total simulation time is $1.6 \mathrm{~s}$.

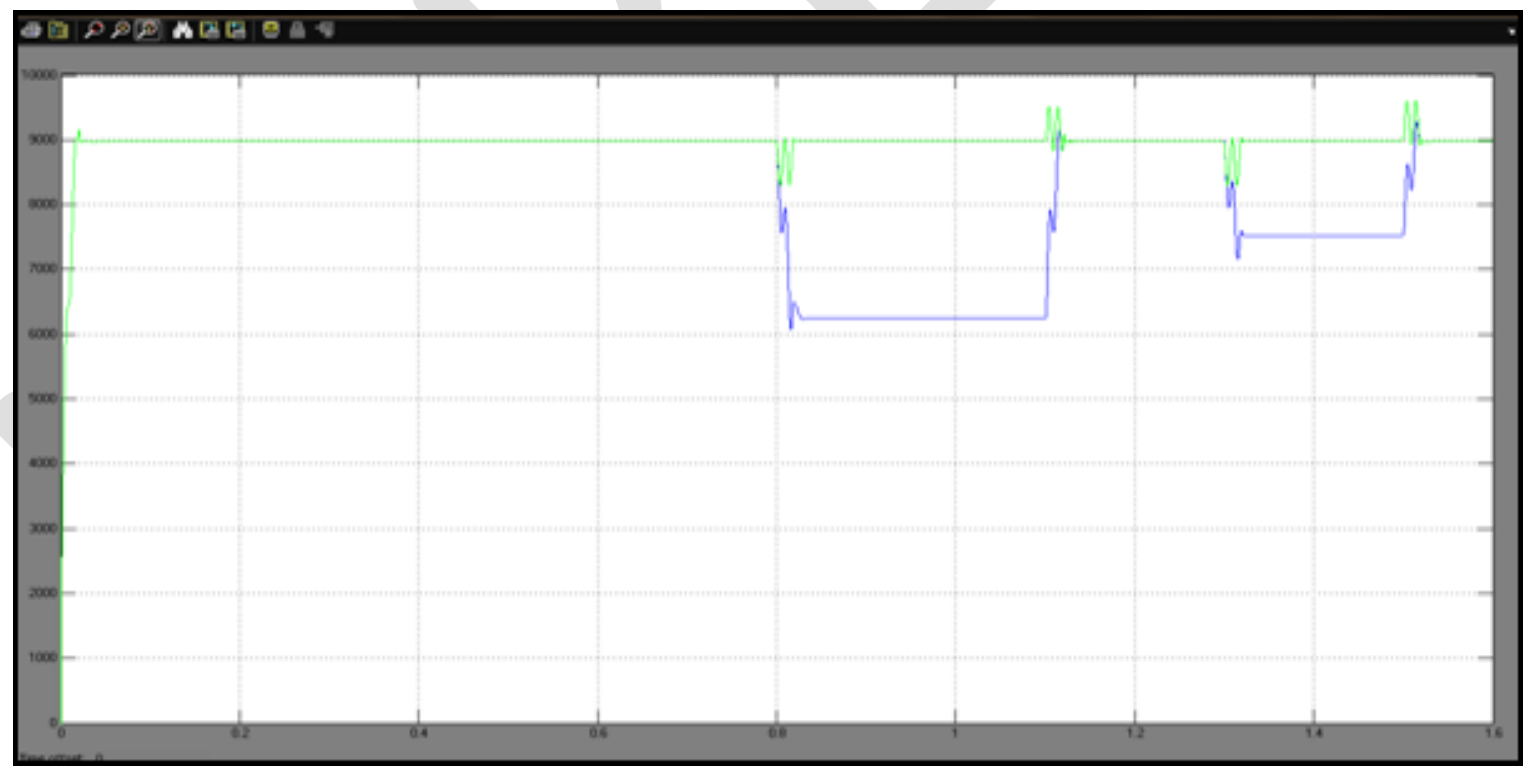

Fig. 5: Three-phase rms voltage across the sensitive equipment and at the PCC.

Fig. 6(a) and (b) shows the results obtained when the linear load (induction motor 1) and the nonlinear load are connected. Fig. 5 plots the line-to-line voltage at the PCC ( $\left.\mathrm{V}_{\mathrm{pccab}}\right)$ : it can be seen that the waveform is distorted, owing to the harmonic currents that the rectifier produces. Also, the total current provided to the linear load, the rectifier, and the sensitive equipment causes a voltage drop at the PCC. The voltage at PCC has an rms value of $10.52 \mathrm{kV}(95.6 \%$ of 


\section{IIAREEIE \\ ISSN (Print) : $2320-3765$ \\ ISSN (Online): 2278 - 8875 \\ International Journal of Advanced Research in Electrical, Electronics and Instrumentation Engineering

\author{
(An ISO 3297: 2007 Certified Organization)
}

Vol. 3, Issue 8, August 2014

$11 \mathrm{kV}$ ) for the fundamental frequency component, while the voltage total harmonic distortion is THD $=8.48 \%$.

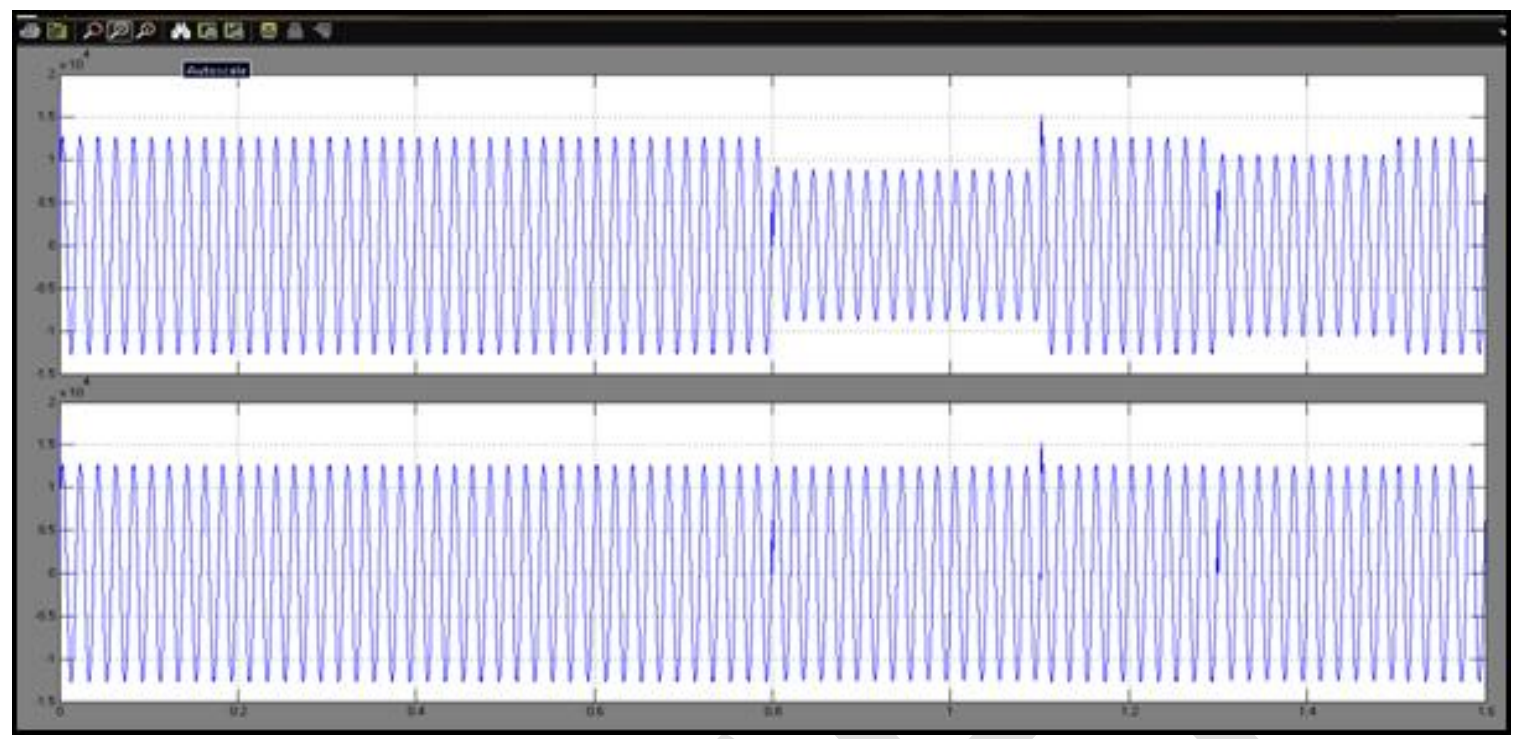

Fig. 6: Line-to-line voltage $(0.6<\mathrm{t}<0.8 \mathrm{~s})$ at the $\mathrm{PCC}$ and across the sensitive equipment

The voltage across the sensitive equipment is plotted in Fig. 7: The DVR, operated by the control system, compensates the unbalanced voltages with a fast transient response owing to the Feed forward term of the sensitiveequipment voltage, while the repetitive control ensures zero-tracking error in steady state. The rms values of the fundamental-frequency components are equal to $11 \mathrm{kV}$ for the three line-to-line voltages across the sensitive load, while the voltage total harmonic distortions are THD $a b=0.90 \%$, THD bc $=1.02 \%$ and THD $c a=0.91 \%$.

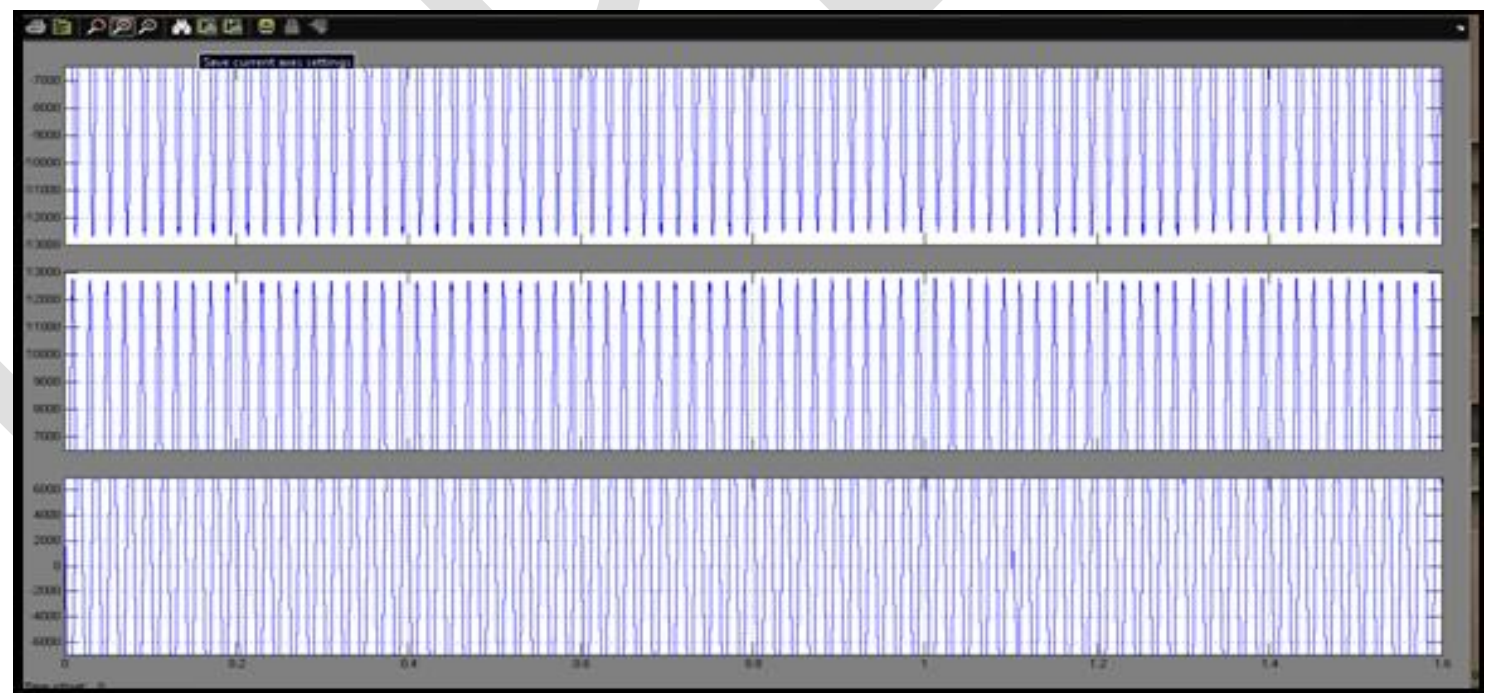

Fig. 7: Line-to-line voltages across the sensitive equipment in kilovolts (a) Vab, (b) Vbc, and (c) Vca $(0.7<\mathrm{t}<1.2)$.

Fig. 8 shows the three output voltages of the five-level converter with reference to the point 0 (see Fig. 1). Since phase B is not involved in the fault, the DVR injects a lower voltage value in this phase than in the other two phases. Therefore, the voltage $\mathrm{V}_{\text {bo }}$ has several unused, unlike $\mathrm{V}_{\mathrm{ao}}, \mathrm{V}_{\text {co }}$ the voltages and, which all use five levels. 


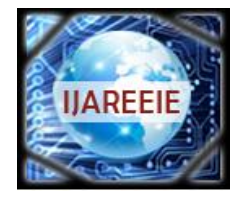

ISSN (Print) : $2320-3765$

ISSN (Online): 2278 - 8875

International Journal of Advanced Research in Electrical, Electronics and Instrumentation Engineering

(An ISO 3297: 2007 Certified Organization)

Vol. 3, Issue 8, August 2014

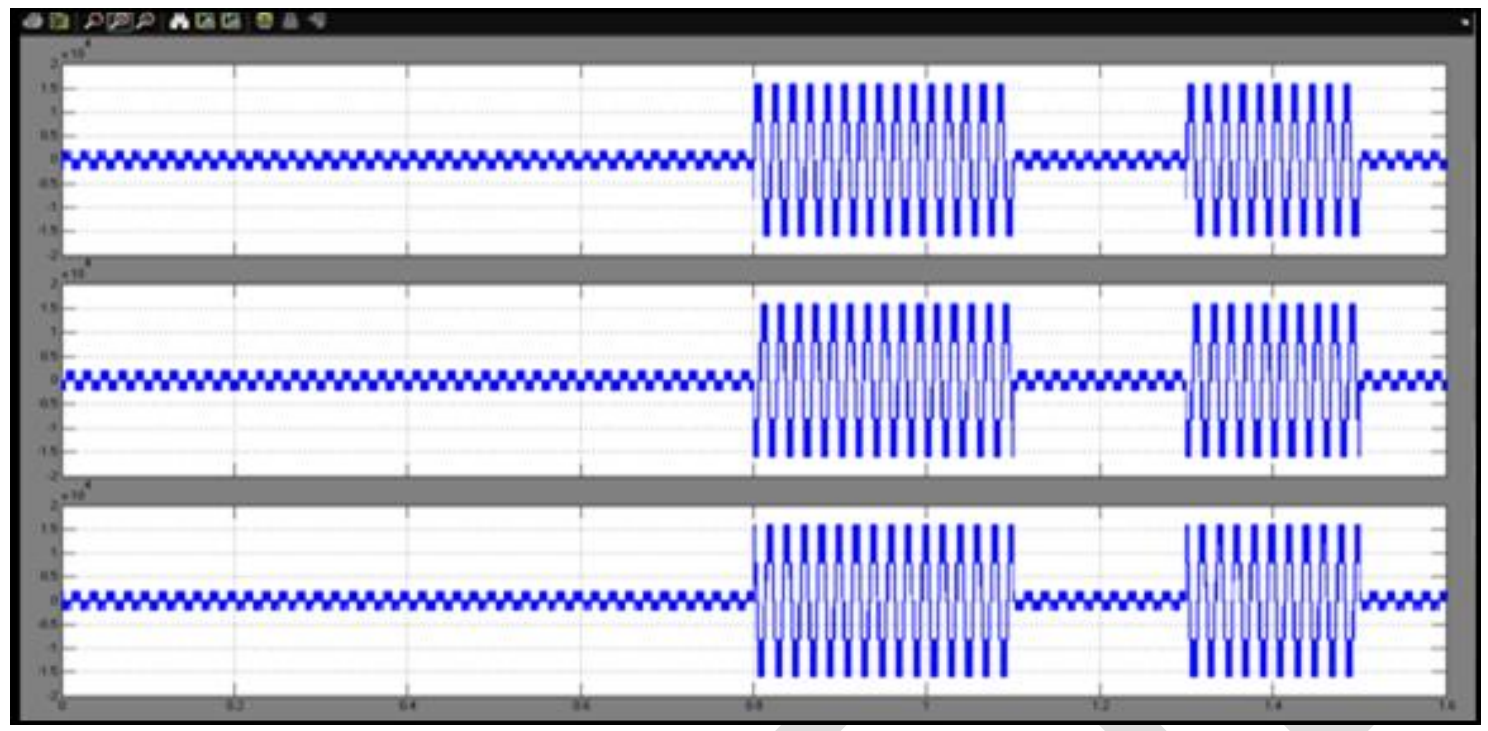

Fig.8: Multilevel-converter output voltages in kilovolts $(0.65<\mathrm{t}<1.14 \mathrm{~s})$

The Fourier analysis shows that the fundamental-frequency component of the line-to line voltage is $11 \mathrm{kV}$ and that the waveform has a voltage total harmonic distortion $0.91 \%$.

\section{CONCLUSION}

In this paper DVR based on a five level flying-capacitor converter operated by a repetitive-control scheme. This control structure simultaneously cancels out voltage sags, voltage imbalances, and voltage harmonics other than highfrequency switching harmonics. The control system is split into three subsystems: the first one works to eliminate the resonance peak of the filter used in the converter output voltage; while the second one is the repetitive control, which ensures a fast transient response and zero-tracking error in steady-state for any sinusoidal reference and for any sinusoidal disturbance whose frequencies are an integer multiple of the fundamental frequency. Finally, the third subsystem maintains constant, balanced voltages in the flying capacitors.

The control system, together with the DVR, has been implemented in MATLAB Comprehensive simulation results using an MV test system show the DVR's excellent performance and the control system in order to protect sensitive equipment from PQ disturbances.

\section{REFERENCES}

[1] M. H. J. Bollen, Understanding Power Quality Problems: Voltage Sags and Interruptions. Piscataway, NJ: IEEE Press, 2000.

[2] V. Immanuel and G. Yankanchi, "A waveform synthesis technique for voltage sag compensation using dynamic voltage restorer (dvr)," in Proc. IEEE Power Eng. Soc. General Meeting, Jun. 2006, pp. 1-7.

[3] N. G. Hingorani, "Introducing custom power," IEEE Spectr., vol. 32, no. 6, pp. 41-48, Jun. 1995.

[4] Z. Changjiang, A. Arulampalam, and N. Jenkins, "Four-wire dynamic voltage restorer based on a three dimensional voltage space vector pwm algorithm," IEEE Trans. Power Electron., vol. 18, no. 4, pp. 1093-1102, Jul. 2003.

[5] L. Xu and V. G. Agelidis, "Flying capacitor multilevel pwm converter based upfc," Proc. Inst. Elect. Eng., Electr. Power Appl., vol. 149, no.4, pp. 304-310, Jul. 2002.

[6] E. Acha, V. G. Agelidis, O. Anaya, and T. J. E. Miller, Power Electronic Control in Electrical Systems. Oxford, U.K.: Newnes, 2001.

[7] C. Feng, J. Liang, and V. G. Agelidis, "Modified phase-shifted pwm control for flying capacitor multilevel converters," IEEE Trans. Power Electron., vol. 22, no. 1, pp. 178-185, Jan. 2007.

[8] J. Arrillaga, Y. H. Liu, and N. R.Watson, Flexible Power Transmission. The HVDC Options. Chichester, U.K.: Wiley, 2007.

[9] A. Ghosh and G. Ledwich, Power Quality Enhancement Using Custom Power Devices. Norwell, MA: Kluwer, 2002.

[10] J. Rodríguez, J.-S. Lai, and F. Z. Peng, "Multilevel inverters: A survey of topologies, controls, and applications,” IEEE Trans. Ind. Electron., vol. 49, no. 4, pp. 724-738, Aug. 2002. 